\title{
The Behavior of Circular Profile Columns Reinforced with CFRP Plates under Combined Gravity and Lateral Loads
}

\author{
Armin Badakhshan and Farhad Ahadi Koloo
}

\begin{abstract}
Today, carbon polymer fibers wrapping are widely used in retrofitting weak and damaged members such as bridge piers and columns of buildings. Columns reinforced with this method enjoy more ductility and energy absorption than other methods, especially the steel shells. The wrapping plays a role in lateral confinement of concrete that can increase the axial compressive strength of the concrete and prevent early failure of columns. This paper performed cyclic loading analysis of thin circular columns with three full wrapping arrangement, middle area arrangement and initial and final arrangements. Results showed that a sample with full wrapping has higher and more regular cycles and greater area under the curve than the other two samples (longer pushover curve); however, the optimal retrofit is using the middle wrapping.
\end{abstract}

Keywords-Carbon polymer fibers, retrofitting, concrete confinement, pushover analysis, cyclic loading.

\section{INTRODUCTION}

In recent years, composite fibers have been increasingly used for retrofitting in the construction industry. Depending on the application of composite materials as well as the style of manufacturing, reinforcement fibers are used as continuous and discontinuous filaments and woven planes. Composite materials under tensile load show elastic and almost linear behavior that retains to the failure instant. There is no yield point in composites behavior and failure of materials is fast and brittle. Concrete compressive stress-strain curve becomes downward sloping after its maximum point, which represents a decrease in stiffness, strength and stability in this range. Given the importance of ductility, avoidance of sudden failure and increased energy loss, the problem should be resolved as much as possible. The problem can be resolved by lateral confinement of concrete.

This can increase the axial compressive strength of the concrete that is a basis for retrofitting concrete columns reinforced with Carbon Fiber Reinforced Polymer (CFRP). Attaching CFRP plates to the outer surface of the reinforced concrete structures members has become a common technology in recent decades. [1], [2]

$$
f_{l s}=\frac{2 t_{s} f_{s y}}{D}=\frac{2 t_{s} E_{s} \varepsilon_{s y}}{D}
$$

Manuscript received October 14, 2016; revised March 1, 2017.

Armin Badakhshan was with Shahrood University of Technology, Iran (e-mail: armin_badakhshan@yahoo.com)

Farhad Ahadi Koloo was with University of Tehran, Tehran, Iran. He is with Esteva Co, Iran (e-mail: Far.ahadi@ut.ac.ir).

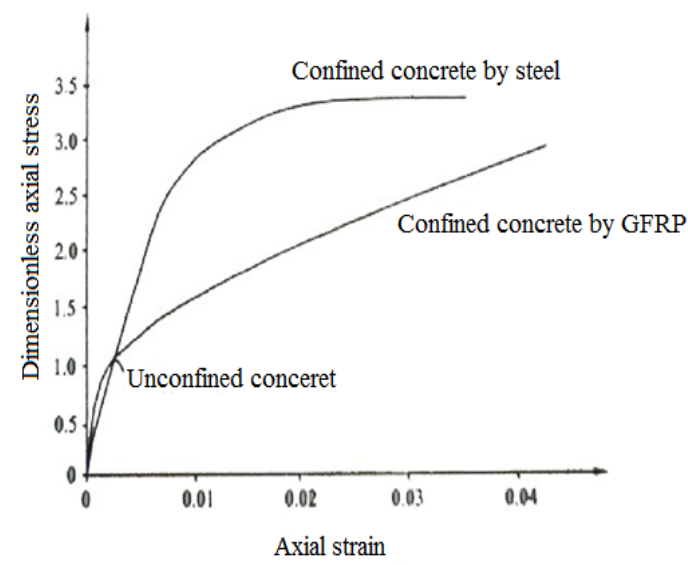

Fig. 1. Unconfined concrete compressive stress-strain diagram, concrete confined with steel and GFRP [3]

Fig. 1 shows that the effect of steel and composite wrappings is normal. Due to its high elastic modulus, steel cover reaches a maximum value coinciding with the appearance of fine cracks in concrete with ascending steep. This amount is proportional to the yield point of peripheral steel, and remains almost constant at the moment of final disposal. Steep of the first rising limb and length of the second area of stress-strain curve of the concrete confined by steel is so large that lateral confinement stress resulting from steel wraps is considered to be equal to a constant amount as equation (1) where $t_{s}$ and $E_{s}$ are thickness and elastic modulus of steel wraps and is the yield strain, respectively.

According to Fig. 1, stress - strain curve of the concrete confined by GFRP composite coincides with the stress-strain curve of conventional concrete before making unconfined concrete compressive strength. Such behavior is slightly considered GERP composite elastic modulus compared to steel. This cause tiny cracks in concrete and small expansions of concrete core in the early stages of loading that produces less tensile force in the composite coverage. After an increase in concrete cracking, graph of stress-strain curve of the concrete confined with composite in the stress equal to compressive strength of unconfined concrete continues with a gradual increase and almost linearly to the failure instant. Equation (2) can be used to calculate the amount of the confining compressive stress that comes from the composite around the column. $t_{\text {frp }}$ and $E_{\text {frp }}$ represent thickness and wrapping elastic modulus of FRP and $\boldsymbol{\varepsilon}_{\text {frp }}$ is its tensile strain, respectively.

$$
f_{l f r p}=\frac{2 t_{f r p} f_{f r p}}{D}=\frac{2 t_{f r p} E_{f i p} \varepsilon_{f r p}}{D}
$$

Quantity in equation (1) concerns with the yield point of the 
steel wrapping. Hence, the result of this equation calculates the confining maximum stress. While equation (2) is proportional to an increase in tensile strain in composite wrapping, it provides an increasing amounts for lateral confining stress. The maximum record of the equation is produced when the composite wrapping strain reaches to its failure strain $\left(\boldsymbol{\varepsilon}_{\mathrm{frpu}}\right)$. [3]

Disadvantages with steel wrappings for repairing compressive components caused the researchers to be attracted by non-metallic materials for improving and retrofitting compressive members. Research shows that extending of the equations provided for the concrete confined by steel to the concrete is confined by composite leads to uncertain responses due to dissimilarities between steel and composite behavior. Thus, new equations were proposed for such confinement, some of which are as follows. In this equation, $\mathrm{f}_{\text {lfrp }}$ is the compressive stress confining the wrapping FRP and is obtained from the equation (2).

Fardis and Khalili [4]

$$
\begin{aligned}
& f_{c c o}^{\prime}=f_{c o}^{\prime}+4.1 f_{l f r p} \\
& \varepsilon_{c c o}=0.002+0.001\left\lfloor\frac{E_{f r p} t_{f r p}}{D f_{c o}^{\prime}}\right\rfloor
\end{aligned}
$$

Miyauchi et al. [5]

$$
\begin{gathered}
f_{c c o}^{\prime}=f_{c o}^{\prime}+3.5 f_{\text {lfrp }} \\
\varepsilon_{c c o}=0.002+10.6\left[\frac{f_{l f r p}}{f_{c o}^{\prime}}\right]^{0.373}
\end{gathered}
$$

Karghari and Gao [6]

$$
\begin{gathered}
f_{c c o}^{\prime}=f_{c o}^{\prime}+\left\lfloor 1+2.1\left[\frac{f_{l f r p}}{f_{c o}^{\prime}}\right]^{0.87}\right\rfloor \\
\varepsilon_{c c o}=\varepsilon_{c o}+\% 1\left\lfloor\frac{f_{l f r p}}{f_{c o}^{\prime}}\right\rfloor
\end{gathered}
$$

Saafi et al. [7]

$$
\begin{aligned}
& f_{c c o}^{\prime}=f_{c o}^{\prime}+\left\lfloor 1+2.2\left[\frac{f_{l f r p}}{f_{c o}^{\prime}}\right]^{0.84}\right\rfloor \\
& \varepsilon_{c c o}=\varepsilon_{c o}\left\lfloor 1+537 \varepsilon_{f r p u}+2.6\left\lfloor\frac{f_{c c o}^{\prime}}{f_{c o}^{\prime}}-1\right\rfloor\right.
\end{aligned}
$$

The major objectives to propose such a study were to present a convenient and optimal method for designing and retrofitting weak and thin columns of reinforced concrete retrofitted with polymer coating under gravity and lateral loads and numerical examination of the effect of different parameters, including changes in the distance of reinforcement, changes in the arrangement of polymer fibers coverage and the amount of different compressive strength of concrete on bearing capacity and energy absorption.

A specimen of circular column of the concrete bridge base retrofitted with carbon polymer fibers is dealt with that was taken from laboratory model of Prof. Amir Mirmiran [8] at the University of Florida. After validation of laboratory specimen and simulated model, other specimens of column were built by different concrete compressive strength and different forms and the results were presented.

\section{SPECIMENS CHARACTERISTICS}

Fig. 2 shows geometric characteristics and how to load the specimens.

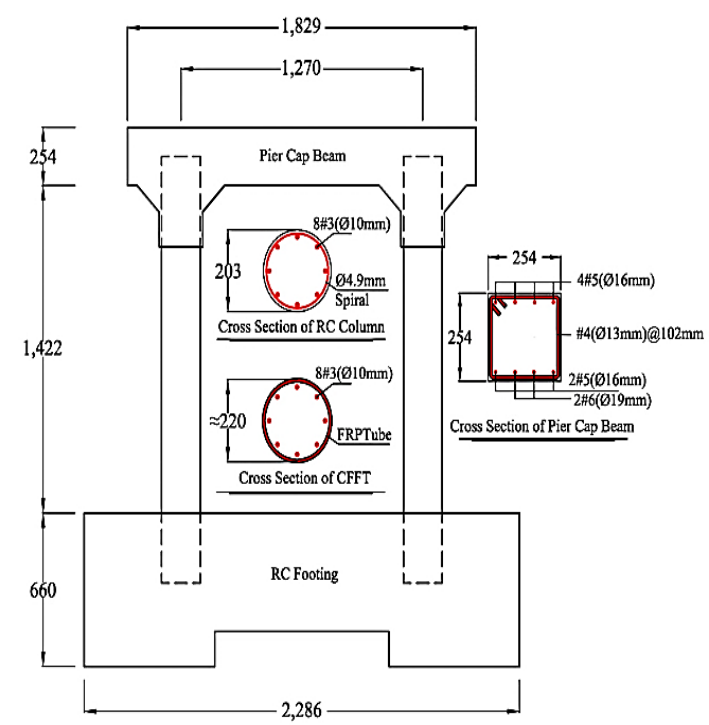

Fig. 2. Geometric characteristics of laboratory specimens.

A cyclic load as shown in Fig. 3 was applied with the help of hydraulic jack on the beam attached to two columns with loading rate of $0.15 \mathrm{~mm} / \mathrm{s}$.

Circular columns with a diameter of $203 \mathrm{~mm}$, eight steel bars with $10 \mathrm{~mm}$ in diameter and stirrups of $9.4 \mathrm{~mm}$ in 200 mm distances were tested in this specimen. It should be noted that compressive strength of concrete used in the entire structure is $44.7 \mathrm{MPa}$. All steel bars have yield stress of 414 $\mathrm{MPa}$, ultimate stress of $646 \mathrm{MPa}$, ultimate strain of 0.095 and starting strain of stiffness of 0.006 . A constant load of $116 \mathrm{KN}$ was applied perpendicularly to the beam in accordance with $0.04 f_{c}^{\prime} A_{g}$.

Fig. 4 depicts force-displacement diagram from numerical analysis and experimental results. It is worth noting that Mander's model was used to define the concrete behavioral model.

Because of the symmetry, in numerical modeling by ABAQUS [9] software, modeling the entire structure was neglected. Thus only one column is simulated and loads have been halved rather than experimental loads; then, outlining results should be doubled in comparison with the 
experimental results. Since the beam which has connected to the two columns was significantly considered stronger than them, no deformation was seen in the beam and it acts as a rigid member.

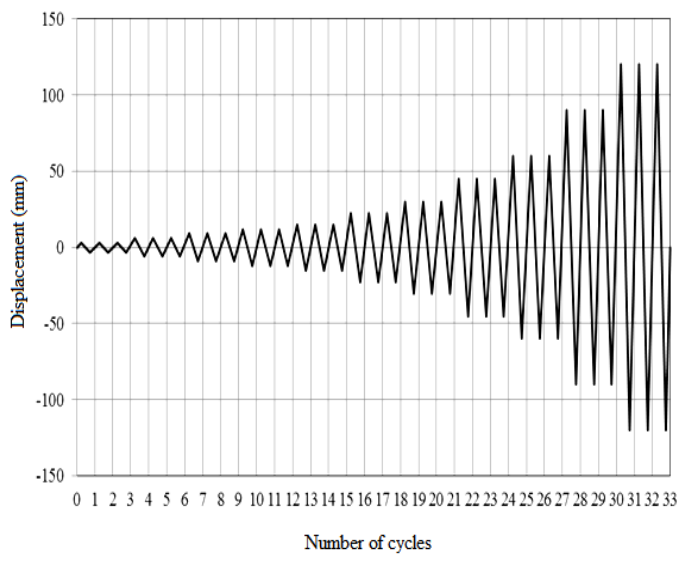

Fig. 3. Loading protocol [8].

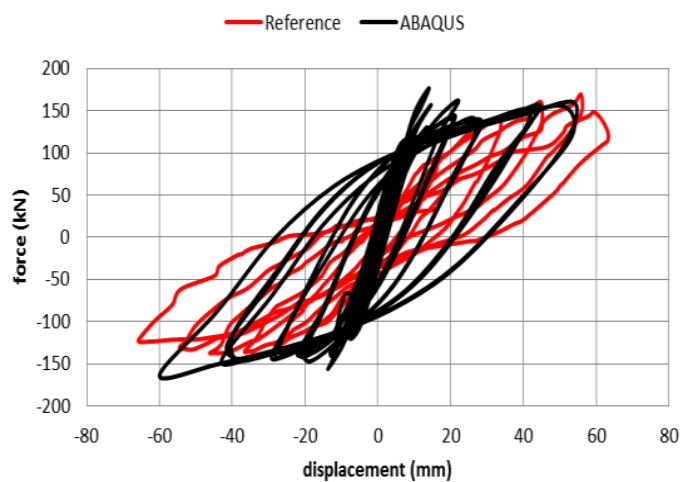

Fig. 4. Comparison of force-displacement curve of the two laboratory and simulated specimens.

According to Table I, the numerical result curve has a reasonable consistency with experimental results. It has the maximum difference of $9 \%$ in some parts, especially in the initial stages of loading. By increasing the load from one cycle to another, the amount of the load after the initial reduction, by retaining the capacity has increased gradually.

Naming columns as $\mathrm{C} 21 \mathrm{CF}$ is as follows: C21 represents concrete with compressive strength of $21 \mathrm{MPa}$, and Final letter can include one of the letters of $\mathrm{F}, \mathrm{T}$ or $\mathrm{M}$, that they indicate full coverage of the concrete column, one-third of the beginning and the end of the concrete surface and one-third of the middle of the concrete column, respectively.

TABLE I. COMPARISON OF THE RESULTS OF LABORATORY AND SIMULATED

\begin{tabular}{|l|c|c|}
\hline \multicolumn{1}{|c|}{ Specimen } & Laboratory & Simulated \\
\hline Initial stiffness (KN/mm) & 47 & 53 \\
\hline Maximum load (KN) & 169 & 177 \\
\hline Maximum relative displacement & 4.4 & 4.3 \\
\hline Ductility & 3.7 & 3.8 \\
\hline
\end{tabular}

In all cases, the distance between stirrups is $32 \mathrm{~mm}$. Table II shows the tested specimens.
TABLE II: INTRODUCTION OF SIMULATED SPECIMENS

\begin{tabular}{|c|c|c|c|c|c|}
\hline & 1 & 2 & 3 & 4 & 5 \\
\hline specimen & $\mathrm{R}$ & $\begin{array}{c}\mathrm{C} 21 \\
\mathrm{C}\end{array}$ & $\begin{array}{c}\mathrm{C} 21 \mathrm{C} \\
\mathrm{F}\end{array}$ & $\begin{array}{c}\mathrm{C} 21 \mathrm{C} \\
\mathrm{T}\end{array}$ & $\mathrm{C} 21 \mathrm{CM}$ \\
\hline Height (mm) & 1500 & 1500 & 1500 & 1500 & 1500 \\
\hline $\begin{array}{l}\text { Diameter of } \\
\text { specimen }\end{array}$ & 203 & 203 & 203 & 203 & 203 \\
\hline $\begin{array}{c}\text { Concrete copressive } \\
\text { strength }(\mathrm{MPa})\end{array}$ & 44.7 & 21 & 21 & 21 & 21 \\
\hline $\begin{array}{l}\text { The number and } \\
\text { diameter of } \\
\text { reinforcement }\end{array}$ & & & & & \\
\hline $\begin{array}{l}\text { Thickness of CFRP } \\
(\mathrm{mm})\end{array}$ & 4.4 & 4.4 & 4.4 & 4.4 & 4.4 \\
\hline $\begin{array}{c}\text { Elasticity modulus of } \\
\text { longitudinal } \\
\text { reinforcement }(\mathrm{GPa})\end{array}$ & 200 & 200 & 200 & 200 & 200 \\
\hline
\end{tabular}

The main objective in all cases is to determine the effect of the main parameters such as type of concrete strength and arrangement of carbon polymer fibers plates on the surface of the thin concrete column on ductility and energy absorption. Moreover, stress - strain curve of concrete is depicted as Fig. 5 that was used in the finite element program ABAQUS.

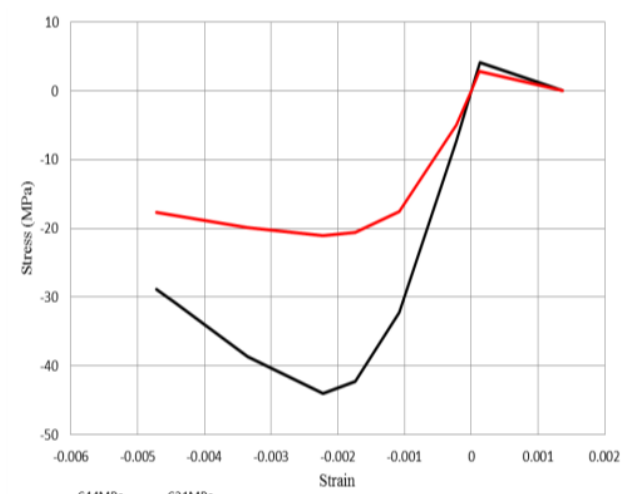

Fig. 5. The stress-strain curve of concrete with compressive strength of 21 and $44 \mathrm{Mpa}$.
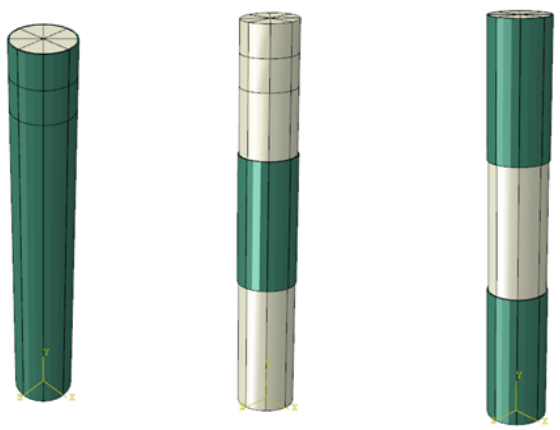

Full coverage The middle one-third coverage One-third of the beginning and end coverage

Fig. 6. Covering circular reinforced concrete column with carbon polymer fibers. 
Fig. 6 shows the coverage of the surface of concrete column reinforced by carbon polymer fibers in three modes. In all cases, cyclic loading was applied to all specimens, and pushover curve of all graphs was depicted after drawing hysteresis curve.

\section{RESUlts AND DisCUSSION OF THE MODELS Simulated}

\section{A. C21C Specimen}

A concrete with compressive strength of $21 \mathrm{Mpa}$, eight longitudinal bars with a diameter of $10 \mathrm{~mm}$ and stirrups of 5 $\mathrm{mm}$ in distance of $32 \mathrm{~mm}$ were used in total length of circular column. No layer of carbon polymer fibers was used for reinforcement of this specimen. Fig. 7 shows the force-displacement graph of the present model.

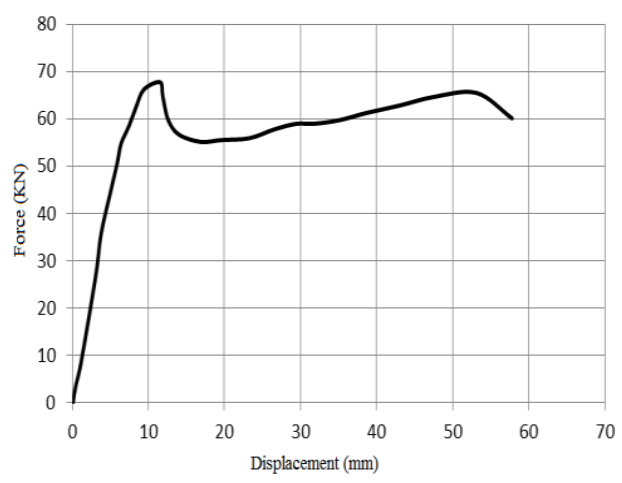

Fig. 7. Force-displacement graph of C21C model.

\section{B. C21CF Specimen}

A concrete with compressive strength of $21 \mathrm{Mpa}$, eight longitudinal bars with a diameter of $10 \mathrm{~mm}$ and stirrups of 5 $\mathrm{mm}$ in distance of $32 \mathrm{~mm}$ were used in total length of circular column. Moreover, a layer of carbon polymer fibers with thickness of $4.4 \mathrm{~mm}$ was used for reinforcement of the total length of the concrete surface. Fig. 8 shows the force-displacement graph of the present model.

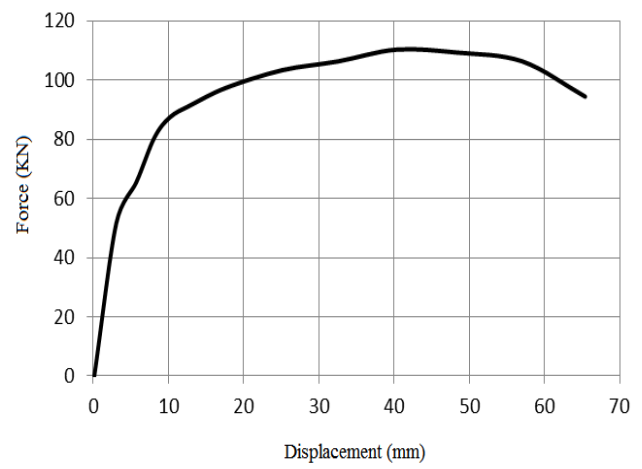

Fig. 8. Force-displacement graph of C21CF model.

\section{C21CT Specimen}

A concrete with compressive strength of $21 \mathrm{Mpa}$, eight longitudinal bars with a diameter of $10 \mathrm{~mm}$ and stirrups of 5 $\mathrm{mm}$ in distance of $32 \mathrm{~mm}$ was used in total length of circular column. Moreover, a layer of carbon polymer fibers with thickness of $4.4 \mathrm{~mm}$ was used for reinforcement of the beginning and ending one thirds of the concrete surface. Fig. 9 shows the force-displacement graph of the present model.

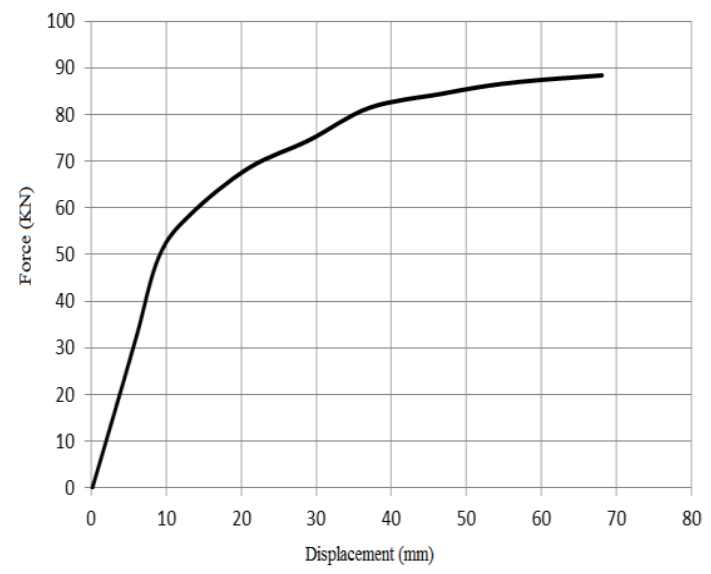

Fig. 9. Force-displacement graph of C21CT model.

\section{C21CM Specimen}

A concrete with compressive strength of $21 \mathrm{Mpa}$, eight longitudinal bars with a diameter of $10 \mathrm{~mm}$ and stirrups of 5 $\mathrm{mm}$ in distance of $32 \mathrm{~mm}$ were used in total length of circular column. Moreover, a layer of carbon polymer fibers with thickness of $4.4 \mathrm{~mm}$ was used for reinforcement of the middle one third of the concrete column surface. Fig. 10 shows the force-displacement graph of the present model.

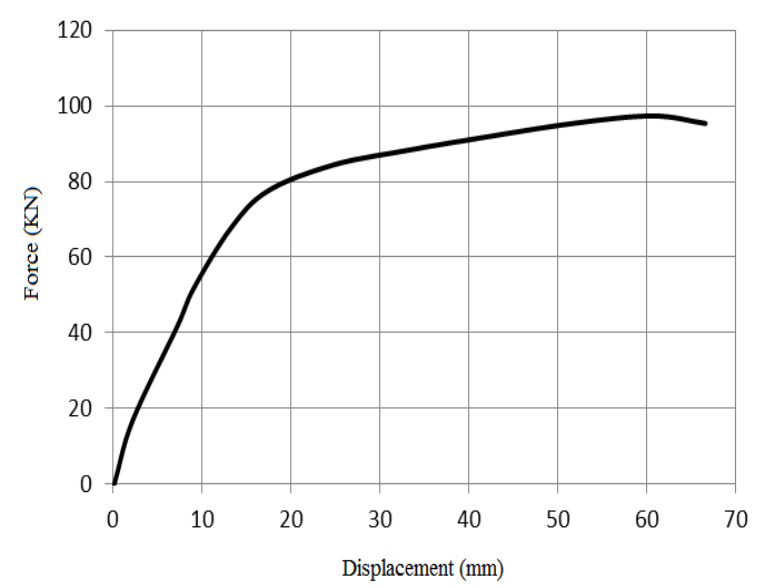

Fig. 10. Force-displacement graph of C21CM model.

\section{COMPARISON OF THE RESUlTS AND DISCUSSION WITH REGARD TO THE LOCATION OF CARBON POLYMER FIBERS PlACEMENT ON THE CONCRETE COLUMN SURFACE}

Fig. 11 depicts the comparative graph of circular columns with compressive strength of $21 \mathrm{Mpa}$ and the changes in arrangement of carbon polymer fibers placement.

As shown in Fig. 11, thin column of reinforced concrete in full coverage status has the highest bearing capacity and ductility. In the $\mathrm{C} 21 \mathrm{CF}$ specimen, final capacity of the section is $62 \%$ greater than the mode where the carbon polymer fibers are not used (C21C). According to Fig. 11, in the case of middle retrofitting of columns (C21CM model) with carbon polymer fibers, bearing capacity is $8 \%$ of the two-thirds of the concrete column surface $(\mathrm{C} 21 \mathrm{CT})$. Table III reports a comparison of the results of recent models. 


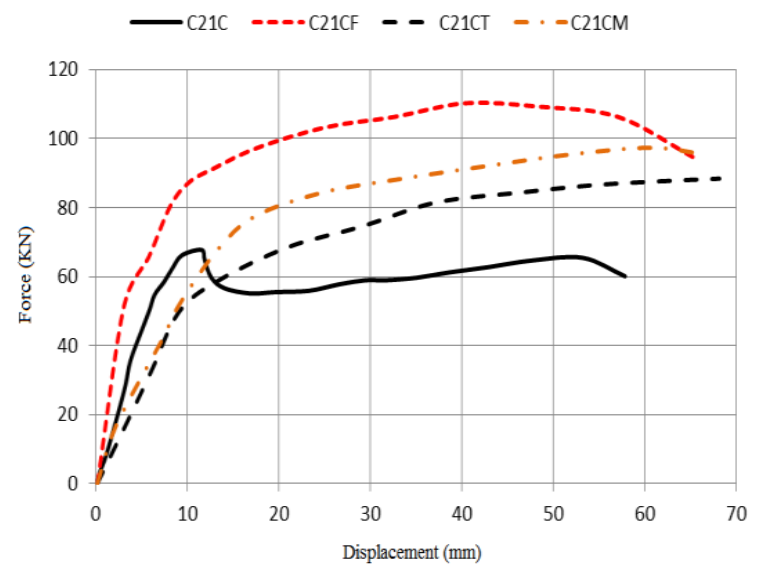

Fig. 11. Comparison of force-displacement graph for circular columns with compressive strength of $21 \mathrm{MPa}$.

TABLE III. COMPARISON OF THE RESULTS OF CIRCULAR COLUMN MODELS WITH COMPRESSIVE STRENGTH OF 21 MPA

\begin{tabular}{|c|c|c|c|}
\hline Model & $\begin{array}{c}\text { Maximum } \\
\text { bearing }(\mathrm{kN})\end{array}$ & $\begin{array}{c}\text { Energy } \\
\text { absorption } \\
(\mathrm{J})\end{array}$ & Ductility \\
\hline $\mathrm{C} 21 \mathrm{C}$ & 68 & 3376 & 2.83 \\
\hline $\mathrm{C} 21 \mathrm{CF}$ & 111 & 5723 & 7.22 \\
\hline $\mathrm{C} 21 \mathrm{CM}$ & 96 & 4408 & 6.5 \\
\hline $\mathrm{C} 21 \mathrm{CT}$ & 88 & 4037 & 6.35 \\
\hline
\end{tabular}

\section{CONCLUSION}

The following results were obtained from the model analyses:

1) Reinforcement of concrete columns reinforced with carbon polymer fibers in all three arrangements increases the bearing capacity, energy absorption and ductility.

2) Results obtained from the diagrams indicate that the use of the full wrapping leads to the largest increase in strength and ductility of the specimens; however, the most optimal case is the use of the middle wrapping, because even though the use of the wrapping in the middle mode is $60 \%$ less than the full wrapping and $30 \%$ than the beginning and ending wrapping.

3) The results of the study demonstrate that middle coverage specimen has about $10 \%$ strength and stiffness more than the first and the last wrapping one. Moreover, the strength of middle wrapping on average is $85 \%$ of the full wrapping.

According to practical project, there are various section shapes; therefore, it is suggested that other section shapes be used for further studies through different combinations of various types of fiber reinforced polymers.

\section{REFERENCES}

[1] H. Sezen and E. Miller, "Experimental evaluation of axial behavior of strengthened circular reinforced-concrete columns," J. Bridge Eng., vol. 16, no. 2, pp. 238-247, 2011.

[2] A. ElSouri and M. Harajli, "Seismic repair and strengthening of lap splices in RC columns: Carbon fiber-reinforced polymer versus steel confinement," J. Compos. Constr., vol. 15, no. 5, pp. 721-731, 2011.

[3] J. B. Mander, M. J. N. Priestley, and R. Park, "Theoretical stress-strain model for confined concrete," ASCE Journal of Structural Engineering, vol. 114, no. 8, pp. 1804-1826, 1988.

[4] M. N. Fardis and H. H. Khalili, "FRP-encased concrete as a structural material," Magazine of Concrete Research, vol. 34, no. 121, pp. 191-202, December 1982.

[5] K. Miyauchi, S. Inoue, T. Kuroda, and A. Kobayashi, "Strengthening effects of concrete column with carbon fiber sheet," Transactions of the JCI, vol. 21, pp. 143-150, 1999.

[6] V. M. Karbhari and Y. Gao, "Composite jacketed concrete under uniaxial compression - Verification of simple design equations, " $J$. Mat. in Civil Eng., pp. 185-193 , 1997.

[7] M. Saafi, H. Toutanji, and Z. Li, "Behavior of concrete columns confined with fiber-reinforced polymer tubes," ACI Materials Journal, July-August 1999.

[8] B. Li, P. Zohrevand, and A. Mirmiran, "Cyclic behavior of FRP concrete bridge pier frames," J. Bridge Eng., vol. 18, no. 5, pp. 429-438, 2013.

[9] H. Karlsson and S. R. I. Pawtucket, ABAQUS, User's Manual, 2013, Version 6.13.

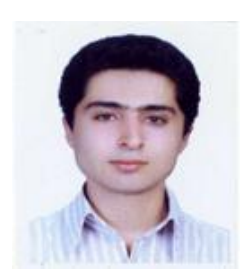

Armin Badakhshan was born in Iran, in 1985. He received his M.Sc degrees in structural Eng. from Shahrood University of Technology, Iran (2011), and his B.Eng. in civil engineering from Qaemshahr Azad University, Iran (2008).

$\mathrm{He}$ started his job as executive director and construction site manager assisstant on residental complexes, Iran (2009), then continued his work as executive director and construction site manager on coastal sattelment, Iran (2013). Also he played Supervisor role for under construction buildings until (2014). He published several papers and books in field of civil and structutral Eng.

Mr. Bdakhshan is member of the Iranian Organization of Civil engineering, and member of Iranian Association of Engineers.

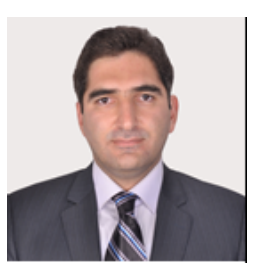

Farhad Ahadi Koloo was born in Tehran- Iran, 1984. He received his M.Sc. in aerospace eng., from University of Tehran, Iran (2014), and his B.Sc. in mechanical engineering from Semnan Azad University, Iran (2008).

Farhad started his job as technical support engineer at Piroozan san-at, Iran (2007), then continued his technical careers in Iran Nazoo pharmaceutical Co, Iran (2013), Geelran motor Co. (2013), and Esteval Technical consultant Co. (2015). As an academic position, he was an engineering lecturer at Mechanical Engineering Department of Pardis Azad University. He published several papers on Strength of Material, Control Engineering and Dynamics, during his educational years.

Mr. Ahadi Koloo is member of the Iranian Society of Mechanical Engineers. 